NEUROETHICS

\title{
Cyborgs and moral identity
}

\author{
G Gillett
}

J Med Ethics 2006;32:79-83. doi: 10.1136/jme.2005.012583

Neuroscience and technological medicine in general increasingly faces us with the imminent reality of cyborgs integrated part human and part machine complexes. If my brain functions in a way that is supported by and exploits intelligent technology both external and implantable, then how should I be treated and what is my moral status-am I a machine or am I a person? I explore a number of scenarios where the balance between human and humanoid machine shifts, and ask questions about the moral status of the individuals concerned. The position taken is very much in accordance with the Aristotelian idea that our moral behaviour is of a piece with our social and personal skills and forms a reactive and reflective component of those skills.

Correspondence to: G Gillett, Professor of Biomedical Ethics, University of Otago, Box 913, Dunedin, New Zealand; grant.gillett@ stonebow.otago.ac.nz

Received 21 April 2005 Accepted for publication 31 May 2005
$\mathrm{N}$ euroscience and technological medicine in general increasingly faces us with the imminent reality of cyborgs-part human and part machine complexes which function as a whole. Indeed the insertion of a shunt for hydrocephalus is one relatively simple example of the creation of such a hybrid. However, the new and revolutionary developments using intelligent componentry to simulate human vision and to link computer circuitry with voice and interactive technology raise the debate to a new level. If my brain functions in a way that is supported by and exploits intelligent technology both external and implantable, then the prospect of cyborgs takes on ethical significance, raising questions about what is a person and how one should treat a partly artificial being, particularly when that artificiality touches the centre of the creature's being.

\section{OUR CYBERNETIC LIVES}

The fact that we have ways of supplementing our own abilities by using artificial devices is a common feature of human life. One need only think of diaries, cell phones, tape recorders, and so on to realise that our cognitive capacities are routinely enhanced by the use of human/artefact relationships and interactions.

However, one quickly encounters a neuroethical version of the Sorites paradox (the paradox of the heap). In its classic version, such a paradox focuses on a category delineated by a quantifiable attribute-such as bald men. We then notice that a bald man does not become hirsute (or not bald) if he has only one hair on his head. But what goes for one can go for one plus one and so on, until we have a man with, say, ten thousand hairs (or whatever it takes so that he counts as no longer being bald). We then realise that it looks as if at some point a bald man has become not bald by merely adding one more hair to his head.

This type of problem recurs, in fact, in all our thinking about complex objects, any example of which can be changed in various non-identity affecting ways to produce a puzzle. For instance, I might say that my grandfather's axe served me well for thirty years after I got it from my father, only requiring five new handles and three new heads. The problem is obvious-"Why is this not a new axe?" In general the problem is: "What change in an object results in a metaphysical difference so that we have a different object (or kind of object) on our hands from the one with which we started?" I am still the moral agent whom people know and react to as me when I use my diary, and when I use my computer; I am myself over the telephone and when I benefit from my antidepressant medication, but how robust is this self who is me in the face of new cybernetic technology and its prospects for enhancement? Would I still be myself if my brain was largely driven by a device that simulated my young adult self in perpetuity?

We can hone our intuitions here on a range of cases.

\section{SOME FANCIFUL CASES}

\section{$\mathrm{H}$ : Head Injury and neurorehabilitation}

Bjorn and Anna have a three year old son, Hansie, with a severe brain injury who, it is predicted, will die. However, they receive new hope when a specialist in "neuroreconstruction" tells them of a technique in which a combination of enzymes, growth factors, and microelectrical stimulation guided by a computer driven three dimensional graphics program could restore Hansie's brain to a potentially functioning state. The process takes about six months because the neuroreconstructive activity takes a similar amount of time to fetal growth and differentiation of the brain. Hansie will lose all his memories, cannot be guaranteed to have the same temperament as he had before the accident, and will require re-education as if he were a newborn baby (he will more or less catch up with his peers about three or four years after his reconstruction). Bjorn and Anna recognise that they are taking on an enormous task but are so overjoyed at the prospect of not losing Hansie and, indeed, having him back in a way that they hope will turn out well in the 
end, that they are more than willing to go ahead.

I will leave aside, for the sake of argument, the ethical concerns about innovative treatment and human experimentation raised by this case and focus on the fact that the procedure contemplated is almost the same as having a new and different child. ${ }^{1}$ In particular the "new brain" is moulded by using sophisticated technology under the guidance of experts who are going to dictate to some extent the way that Hansie's cognitive and personality characteristics are formed. Should they be allowed to think of this child as still being Hansie and does our ethical attitude to what they are doing depend on how we answer that question? I would say that they can and that it does not even though some theories of personal identity would render both of these stands problematic. The justification will emerge below.

\section{V: Vision restoration through cybernetics}

It is currently possible to provide blind patients with surrogate vision sufficient to detect things in their environment by using a combination of video camera technology and an array of electrodes delivering impulses to the patient. Let us imagine that the technology reaches the point where the electrodes are directly onlaid so that they stimulate the brain and the person concerned then uses the information in the patterns of excitation that are set up to exploit their visual environment.

If such technology was successful then, I think, we would have little moral concern even though a cybernetic brain was playing an important part in a human individual's adaptation to their environment and, presumably, influencing that person's thoughts and feelings about the world to some extent. Our intuitions here seem to be based on the fact that the core of the person, that which defines his or her identity and relationships remains untouched by this technology which functions very much like an add on or prosthesis used in service of a life with its own holistic integrity.

\section{HC: Extensive brain injury and replacement with micronetworks}

Henri-Charles's neuroreconstruction is very similar to Hansie's, with one difference: it is facilitated by and incorporates a set of relatively modular microchips with the capacity to respond to biological signals generated by cell membranes and neural cell columns. The modular chips subserve some of the well established functional connections that are known to occur in the human brain to do with sensorimotor interaction in perceptual cycles and some stereotypical responses such as those involved in affect programs, and some of the assemblies created replace damaged neural tissue.

This case is exactly like the Bjorn and Anna case and is also science fictional. In this case the result is a truly cybernetic brain in which a number of centralised and widely connected functions (such as affect programs ${ }^{2}$ ) are designed in ways which exemplify general patterns of connectivity. These are then integrated into the cerebral neurocognitive system in an idiosyncratic way by the individual concerned, which is similar to what happens during neurorehabilitation. Our intuitions are thrown, however, by the fact that some of the human reactions and responses that Henri-Charles will come to exhibit may be cold, calculating, and robotic in ways that disengage him from the moral community at important points; we can almost hear the humming of the circuits which plan and execute his responses. The thought of his alien rather than fully flesh and blood nature tends to capture our thinking and make us wary of him: but such prejudice will not do for moral thinking and we need something to take us further than conjecture and somewhat unconstrained imagination.

\section{A: Anencephaly with brain simulation}

Bryn and Lilith are "older" parents with Lilith not expecting ever to have another child. Unfortunately the child who is to be born to them, whom they had intended to call Arlo, has been shown by intrauterine scans to be almost anencephalic and his brain, though covered by intact skull and skin, is only a series of membranes containing spinal fluid draped over a primitive brain or brainstem like structure comprising rudimentary neural assemblies and circuits connected to the top of the spinal cord. They are approached by Dr F whose neurosimulation team offers to use cells taken from (to be) Arlo's umbilical blood and primitive neural tissue to interface with a cybernetic assembly reproducing much of the complexity of a neonatal brain. They have used this technology in some higher animal infants with severe developmental abnormalities of the brain and these creatures have taken on characteristics virtually indistinguishable from those of normal individuals of their species.

The case of Arlo is an entirely fanciful projection (to a certain limit) of possibilities raised by visual simulation and HenriCharles and it confronts us with the cyborg issue in a stark way. It asks the question: "What is it to be human" in a way that does not seem so pressing for the cognitively similar case of Hansie. Some might regard this as so fanciful that they cannot form any clear moral intuitions but the sources of unease are laid out in the case of Henri Charles and so I will offer one more thought experiment on this topic to enrich the grounding of our intuitive reactions.

\section{P: Personality upgrade with micronetworks}

The following story extends our intuitions about cyborgs (in a similar way to the film Bicentennial Man).

Peggy and Bob are married but, sadly, not happily so. They began married life as a fairly typical young married couple but then Peggy fell prone to episodes of depression, spending more and more time at home, not working, and lamenting her inability to have children. She has tried antidepressants and psychotherapy but no progress has been made and she has increasingly taken to her bed, neglecting herself, her marriage, and any hope of a career. Bob is desperate as he is increasingly fearful of leaving her alone. His aunt mentions an excellent service, "Cybo-help", that provides androids for just such cases. $\mathrm{He}$ goes to the centre and is shown a recently released companion/carer model mainly used for caring for older folk but which can be used also with young disabled people. He purchases an android, calls it Andrea, and takes it home.

Andrea is marvellous. She brings tea in bed, does the work unobtrusively, spends endless hours talking to Peggy, patiently involving her in various activities so that she more than lives up to the " $\mathrm{C}_{\mathrm{c}}$ " (for Compassion and caring circuit) that she has embossed behind the hairline of her right temple. Peggy loves her. Bob knew about the compassion circuit and also that others were available: $\mathrm{V}_{\mathrm{s}}$ (Vivacious and sociable); I (Intellectual); A (Artistic), 
and so on. Quite soon he also finds that he thinks of Andrea as a person.

After an extended business trip he comes home to a Peggy who has made significant gains in her psychological functioning and he finds that she has had some treatment in the revolutionary neuropsychiatric clinic recently opened in their city. She is the Peggy he married-active, positive in her attitude, and relaxed about life. After his next trip he finds she has taken up watercolour painting and joined a reading group. In fact, Peggy has improved so much that when the time comes to renew Andrea's lease, she is returned to "Cybo-help".

Bob and Peggy miss Andrea but are very much happier than they have been for years until one night. Bob is stroking Peggy's hair and feels a row of letters embossed in her scalp behind her hairline.

\section{Should he worry?}

\section{ETHICS AND THE HUMAN: INTUITION AND REFLECTION}

The spectre of robots with human attributes has always been the stuff of science fiction but advances in implantable microchip technology and prosthetic devices which can interface smoothly with the human brain make our moral concerns a lot more pressing than they used to be. In the cases I have described we find ourselves left at tantalising points with one or two prima facie (and very broad brush) pegs to hang our thinking on.

(i) We are less concerned when the cybernetic components of the person seem peripheral or somewhat incidental to their psychological identity or character.

(ii) We are more concerned where a non-human mode of relationship and reaction or response to others may affect a person at a very deep and pervasive level.

A moment's reflection, however, on our intuitive idea that a machine, no matter how human like, is not a candidate for moral properties, reveals that it is an idea that is hard to justify. It is even harder to emotionally sustain after a film like Bicentennial Man or AI, where we see the world through the narrative eyes of such a character. When we do that we are drawn to identify with them and realise that they strike many of the same balances that we do between expedience, attachment, sensitivity, and so on.

It is on the basis of just such things that we have moral attitudes to human beings such that we regard it as wrong to do certain things to them and feel that it is good to treat them in certain ways and show them certain kinds of consideration. The peculiarities of those attitudes are internally related to exactly the properties of relatedness, vulnerability, and so on that arise between people. Our attitudes to human beings and their interests are distinguished by these features from the sense of right and wrong that applies quite straightforwardly to machines. It is wrong to put diesel fuel in my car and we understand what is meant when someone says that a machine is "happy". These evaluations are related to functions for which the artefacts in question have been designed and they differ from evaluations of right and wrong in human cases in part because there is no agenda belonging to the individual or robust subjectivity to provide a point of application for our sympathies in such cases. The relationship is entirely functional and instrumental and there is no admixture of organic intertwining of feelings and first person narratives in our dealings with machines. We can make this thought vivid by imagining a practical joke that would work in a stage one philosophy class. Imagine a group of first year philosophy students turning up to their tutorial and being confronted by a tape recorder. When they are seated the tape recorder "says" in a mellow female voice "I think, therefore I $\mathrm{am}^{\prime \prime}$. The group laugh. The tape recorder goes on, now sounding a little desperate, "Don't laugh at me!"

The group look quizzically at each other.

The tape recorder, in a pleading tone, says: “Ok, Ok, I know why you are looking at each other like that, but just believe me I got morphed into this form and I am desperate for human interaction".

As one of the group points at the recorder and says, "What's with this thing", the recorder says, "Please, don't turn me off, I live for these times!"

Now this tape recorder may sound and appear to cogitate and interact with us exactly like a creature that we believe to be a soul (a moral existent among us) but we do not believe that it is one. We do not think that the simulated narrative and subjectivity are anything more because the parameters of function are explicable on a much more parsimonious basis. We are similarly not fooled into entertaining the thought that cyberpets who need petting and talking to or they "die", are anything but clever simulations on hand held computers even though they are designed to respond somewhat like real pets. Wittgenstein makes a telling remark about non-human souls.

Look at a stone and imagine it having sensations. One says to oneself: how could one so much as get the idea of ascribing a sensation to a thing? And now look at a wriggling fly and at once these difficulties vanish and pain seems to get a foothold here, where before everything was, so to speak, too smooth for it. ${ }^{3}$

He is surely right in that we cannot get our heads around the idea that suffering is or could be manifest in the sense that it matters morally (rather than a gearbox graunching and us wincing with the metaphorical "pain" of it, or a cyberpet showing a "sad" face) when its "subject" is not a living flesh and blood creature. But even (animal) pain or pleasure in and of themselves seem a little "thin" to form the basis for substantive moral attitudes (though we might not feel morally comfortable with the treatment of flies by wanton boys). But the mortality and sufferings of organisms such as tapeworms and insects are traditionally of no account alongside that of the cats and dogs we treat by eradicating them, so we have to do a bit more work to get to the reason why it is that the grimaces, writhings, and struggles of a tapeworm or an eel (as for an android) "do not cut it" for us in terms of moral engagement. The thought is that these things are much too limited to be ends in themselves or have subjectivities of their own and can only supplement the stories they figure in which have a narrative point of subjectivity located elsewhere. We are interested in the subjectivity at the centre of the story and need that posit to be credible in order for the being to engage our moral concern.

We can refine our intuitions further by considering the kind of goodness and badness we recognise in our treatment of animals (even when we find their reactions to what we do quite inscrutable). For instance, it seems undeniably good to provide suitable conditions for an orang utan, for whom we may think that there is an absolute sense of good linked to having available a rain forest habitat in which its nature can be expressed. This natural kind of good is regarded as a kind sufficient for generating a robust conception of human goodness by some contemporary writers. ${ }^{4}$ Whether or not that is true, we can understand the idea that such attitudes concern our being and have genuinely ethical subject matter. ${ }^{6}$

If, however, artefacts cannot get into the moral domain through any resemblance they may have to organisms, despite their cognitive engagement with us, what is doing 
the "soul work" here? Somewhere in the scale of organisms we get to the kind of pleasure and pain and other responses that move the creature concerned into the moral domain for us. How do we begin to understand that point? I have gestured at clues to be found in the idea of a narrative.

"Hal" from 2001, a Space Odyssey comes across as a moral agent because of the way he interacts with human beings and establishes a cognitive/intellectual rapport with them (as distinct from the more "earthy" organismic rapport one enjoys with a living creature). We also get the sense that he has a history that he is living through. Descartes's tape recorder goes some way towards doing the same as Hal when he fills in his background for us and a cyberpet may simulate the sense of life at stake were it to "remember" its history of relationship with its owner, convey disappointments, recriminations, joy at being awakened by its friend, and so on. In each case it is understandable that we treat the other to whom we relate as a moral being because some aspects of our normal ways of interrelating with moral agents are in play and we fill in the rest (in the way human beings are cognitively prone to do). Most of the time this "filling in" is, of course, entirely appropriate because the being before us cognitively manifests at any time only a subset of a complex constellation of natural abilities and capacities (including those which give rise to moral reactions, responses, and exchanges that justify and reciprocate our regard for them) that are developed in living out a life story among others. The filling in or ascription of a moral state of being to an interlocutor then draws on a history of similar encounters to generate its own momentum and cumulative content (where it is reciprocated). Thus we are souls whose lives intersect in the moral realm.

\section{WHAT IS A HUMAN SOUL?}

The soul, for an Aristotelian thinker, is a complex and integrated whole emergent from a set of biological and psychological functions that characterise a creature of a given type. Aristotle discusses this in De Anima ${ }^{7}$ and also in Nichomachean Ethics, ${ }^{8}$ and this view is neatly summarised by Locke in his Essay on Human Understanding. ${ }^{9}$ A human being has vegetative, animal, intellectual, and social or political functions which combine to give individual form to the life a person lives among his or her fellows. We could say that the narrative continuity of the human soul is based on the temporally extended flesh and blood existence of critters like us and the individual encounters that shape each one of us. ${ }^{10}$

There are other bridges between this state of normal or natural existence and some of the fanciful scenarios envisaged above. We could say that the "programs" composing a human mind (with its unique memories) and enlivening a human body are a product of learning history and the cumulative effect of relationships with other human beings in a given historicocultural context. This can, however, be made to sound very Cartesian and thereby leave the body out of the picture in a way that prompts some of the questions about the moral status of cyborgs.

What is so morally important about protoplasm? And what is so morally important about human protoplasm in that instead of silicon microchips doing the work of the "character circuits" we could, perhaps, produce neural assemblies, genetically engineered from yeasts or other protoplasm-for example, pig-that would be functionally suited to producing the right kinds of cyborgs when equipped with humanoid heads?

Interacting with and characterising creatures rests on two related things: (i) reactive responses to those things; and (ii) representing to ourselves the form of a thing and factoring that into our reasoning about our treatment of it. An Aristotelian recognises that a particular form of an object, say a chair, realised in bronze, is not the same as one similar in every other respect but realised in wood. In the case of a soul we can imagine a holism about the habitus (including responsivity, energy, and vulnerabilities among other things) of a human being that is uniquely grounded in human flesh and blood and cannot be reproduced in silicon, any other fabricated material, or even different flesh. We could argue that the human being combines uniquely feeling, fleshly contingency, and intellect (broadly construed) in a holistic way that defies reductive analysis so that even this three point delineation is somewhat crude and misleading. We would then need to make plausible the idea that only a human being with the holistic nature that implies can live out our kind of subjectivity (a thought that is not that inaccessible-could you come back as a being differently gendered from the one you are).

It now begins to seem as if it is the total form that is revealed in a lived life story that gives a being the identity which matters morally and that identity, in the sense we respond to it in our moral thinking, is somewhat indifferent to the material of which the being is made except in so far as that material affects the relevant lived experience (which is not independent of how we react and respond). Thus, for instance, if a person could not respond to me in a characteristically human way because the megabytes that control them are unresponsive to the hormones and biochemical changes that influence many human reactions and feelings, then the contribution of the artificial aspects of the cyborg (to the whole being with whom we are interacting) has affected the being of the (candidate) person in a morally relevant way and we might find that moral responses and judgments differing in important ways from our responses to our fellows are appropriate. It seems to be just this intuition that Shylock appeals to when he makes his famous "Hath a Jew not flesh and blood" speech to highlight his congruence of reactions with those judging him. We can imagine this not working with Arlo and the transformed Peggy but ringing true in the case of Hansie. Our intuitions about Henri-Charles are I think sufficiently shifting for us to have to "see how it goes".

To this holistic appreciation of the fact that one is in the presence of a critter like oneself one brings a certain reflective or perceptual equilibrium, involving both intuitions and a rational analysis of the facts surrounding relevant encounters and their characteristics. ${ }^{10}$ In the end, however, one judges according to the responses one finds evoked in oneself and their sustainability over time, and to reflection, in much the way that the Aristotelians claim. Faced with this strange moral fruit we, "suck it and see". I cannot, however, see that the tissue of which one is composed has, apart from its effect on the individual's ability to participate in our forms of life, any more moral relevance than the colour of one's skin in our relationships to that being. Is the being before me able to feel pain? Does the being before me develop attachments and make an appeal to me? Does the being before me have a story in which moral participation features? What we ought to do seems to be the result of the myriad normative demands and imperatives that we are inculcated into in our daily interactions with those who shape us into the individuals we are.

Others shape me by imparting skills, for instance of self direction and self formation, that enable me to take some control over the directions in which my life goes. I obey those "oughts" and "shoulds" or reject them and grow as an individual in the shared soil of my culture and my land. Thus we are beings who have inscribed deeply into us our ways of being that include belongings, oughts, and desires, inspirations and aspirations, skills and styles of moving, sources of energy and hesitation, taboos and permissions, and so on. 
Therefore what we ought to do is to be true to our nature as beings who live as members of a kingdom of ends able to recognise, take account of, and respond to each others' subjectivities as they are revealed in lived experience when we interact with each other and tell our stories. ${ }^{11}$ For that reason, in any imaginable case, I think we ought to react on the basis of a sum, albeit complex, dynamic, and impossible to reduce to formulations, of the mutual participation in language games where morality is relevant. On the basis of that complex engagement in a many faceted discourse, our conception (metaphysical if you like) of what a human being is is derived from the beings with whom we share these formative and sustaining interactions.

\section{THE CASES REVISITED}

The cyborg cases can now be resolved (or at least approached with resolve). In each case we evaluate somewhat informally the extent to which we have a genuine human being among us on the basis of myriad cues that are manifest in our forms of life. These cues and clues are drawn for us by our dealings with the persons in question and reactions (or reactive attitudes $)^{12}$ are evoked in us depending on our dispositions within the kingdom of ends that is human society (and we know that we can be conned so as to indulge unsustainable illusions). Realism of the type we are challenged about in our moral reactions to cyborgs is therefore not solely a product of disengaged metaphysics but of engaged and holistic discourse in which we participate by exercising sensibilities built on charity and a number of other virtues so that our ways of knowing the moral sphere and its inhabitants are themselves moral (or ethical). In near human cases we hope we will not get off on the foot of judgment but rather explore the path of acceptance and then let our reactive attitudes be tempered by judgment where it proves necessary. We may find ourselves living at a frontier where all things are a matter of degree but then the human mind, released from a naïve commitment to the finality of stereotypes and categorical judgments, has negotiated that kind of terrain before and done best when it has done so with humanity. On this basis, Hansie is one of us, not only because he is flesh and blood of the right kind, but also because he has not "died" in any culturally validated sense. He has, in terms of the experiences of his kith and kin, been severely injured and nursed back to health and he belongs, as a restored Hansie, to us in the same way as he always did.

We are left with the problem of Peggy, a problem bedevilled by the question: "What has happened to the real Peggy?" This problem keeps company with the thought that there is an android intelligence in Peggy who may be like a second personality-knowing but not known and ultimately able to perform a coup aided by a scheming cyborg, Andrea. This problem is an epistemic, metaphysical, psychological, and forensic conundrum but I would argue that the epistemic virtues needed to gather the data relevant to the metaphysical question cannot be exercised in the absence of the right moral attitudes.

It therefore seems to me that a cyborg is, on the present account, as human as his or her life among us indicates to those who approach the encounter with an openness to others and a sense of life. The creature concerned ought then to be treated as such an acquaintance would treat them.

\section{REFERENCES}

1 Gillett G. Bioethics in the clinic. Baltimore: Johns Hopkins University Press, 2004, ch 15

2 Griffiths P. What emotions really are. Chicago: University of Chicago Press, 1997.

3 Wittgenstein L. Philosophical investigations. Oxford: Blackwell, 1953:284

4 Foot P. Natural goodness. Oxford: Oxford University Press, 2001.

5 Hursthouse R. Normative virtue ethics. In: Crisp R, eds. How should one live? Oxford: Oxford University Press, 1996:19-36.

6 Gaita R. The philosopher's dog. London: Routledge, 2002.

7 Aristotle. De Anima [trans Lawson-Tancred H]. London: Penguin, 1986.

8 Aristotle. Nicomachean ethics [trans Thomson JAK]. London: Penguin, 1953, especially at 1097b27-1099b9; 1 102a13-1103a10.

9 Locke J. Essay concerning human understanding [ed Nidditch P]. Oxford: Clarendon, 1975, bk II:xxvii, 8.

10 Gillett G. Form and content: the role of discourse in mental disorder. In: Fulford B, Morris K, Sadler J et al, eds. Nature and narrative. Oxford: Oxford University Press, 2003:139-54.

11 Rawls JA. Outline of a decision procedure for ethics. In: Thompson J, Dworkin G, eds. Ethics. New York: Harper and Row, 1968:48-70.

12 Strawson P. Freedom and resentment and other essays. London: Methuen, 1974 